\title{
CORRESPONDENCE
}

\section{DIAGNOSIS OF DIPLOPIA}

To the Editorial Committee of the BrTtish Journal of OpHTHALMology

Sirs,-The article by E. C. Cowan (Brit. J. Ophthal., 1960, 44, 59), describing a simple apparatus for the diagnosis and recording of diplopia, prompts me to make a few observations.

His instrument uses a method not unlike that which I described some years ago (Brit. J. Ophthal., 1949, 33, 54) and which is still available in an improved form called the "Lees Screen" from Theodore Hamblin Ltd. Mr. Cowan appears to be unaware of this screen as he does not mention it in his article.

My early experiments led me to conclude that the use of a small screen, as in Mr. Cowan's apparatus, because of the short working distance involved, leads to errors from the eyes converging secondarily to the accommodation which is brought into play.

The need to invert the screen by such a method as Mr. Cowan's was recognized by me, and was obviated on my screen by a double mirror and by screens on which the tangent scale is invisible until illuminated, so enabling the testing of each eye without moving the screens in any way.

I came to the conclusion that portability, although occasionally convenient, was better sacrificed for the benefits which a larger and more refined, though static, instrument conferred.

Royal Albert EdWARd Infirmary, Yours truly, V. T. LEES. WigAN, LANCS.

February 24, 1960.

\section{BOOK REVIEWS}

Dynamic Electroretinography in Ophthalmology. (L'électrorétinographie dynamique en ophtalmologie.) By G. E. JAYLE, R. L. Boyer, and R. L. CAMO. 1959. Pp. vi + 161. Masson, Paris. (41s.)

After 20 years of hard work, electroretinography has still not been shown to be of any real clinical significance. Any attempt to increase its usefulness is to be applauded. The authors of this monograph have evolved a technique which enables them to record the ERG during the various phases of dark adaptation, and in response to flicker and light of different wavelength. They can assess these records in many different ways.

But, in order to gain useful information from such records, it is necessary to have sound knowledge of the basic physiology of vision and the physics both of the recording situation and of the instrument one uses: in these respects this work is unsatisfactory. The review of previous work is superficial and frequently incorrect, and the section on technique and possible errors is inadequate. These authors do not use non-polarizable electrodes. They do not immobilize the pupil (though they investigate the results of alternating stimulus intensity). They use an inadequate time constant $(0.3 \mathrm{sec}$.) and a pen-recorder which is not only incapable of following changes with the desired rapidity, but also writes 